\title{
¿El poder llegó a su fin?
}

\author{
Diego Andrés Villamil Silva \\ (Diego.villamils@outlook.com )
}

NAÍM, Moisés (2013). El fin del Poder. México D.F., México: Editorial Debate. 440 pp.

Esta es una reseña de un libro sobre el poder. Básicamente, aquello que motiva a la gente; aquello que los gobernantes buscan tener, y, -una vez teniéndolo-, conservar y aumentar. Por lo menos ese es el consenso de muchos filósofos, como Maquiavelo, Hobbes o Nietzsche. Simpatizando con lo anterior, Moisés Naím expone su definición de poder -cuyo enfoque evoca un ensayo del politólogo Robert Dahl: "es la capacidad de dirigir o impedir las acciones actuales o futuras de otros grupos e individuos. $\mathrm{O}$, dicho de otra forma, el poder es aquello con lo que logramos que otros tengan conductas que, de otro modo, no habrían adoptado" (p. 38). Además, precisa que es una fuerza que implica necesariamente una relación entre dos o más protagonistas: "Nadie se pasea con una cantidad fija y cuantificable de poder, porque, en realidad, el poder de cualquier persona o institución varía entre una situación y otra" (p. 39).

Moisés Naím, reconocido columnista, analista de economía y política internacional, doctor por el Massachusetts Institute of Technology, publica El Fin del Poder en octubre de 2013 - The End of Power, su título original. Aunque fue en 1989, a partir de una experiencia que él dice haber vivido intensamente -fue nombrado ministro de Fomento de Venezuela en ese mismo año-, de donde extrajo una lección que comprendió mucho tiempo después y le sirvió para construir su tesis. Dice que, la percepción que a menudo se tiene sobre las capacidades con que cuenta quien posee el poder, es errada; se le atribuyen facultades que cada vez son más limitadas, debido a que el poder está sufriendo mutaciones 
muy profundas. "Los poderosos tiene cada vez más limitaciones para ejercer el poder que sin duda poseen" (Naím, 2013, p. 15). "El Fin del Poder" es un libro fácil de leer, es ilustrativo y va dirigido a todos los ciudadanos del mundo. Quiero decir, a cualquier persona sin importar si se dedica a estudiar las Relaciones Internacionales o no pues los cambios que está sufriendo el poder nos pueden tocar $-\mathrm{y}$ nos están tocando-a todos. La humanidad ha sufrido grandes cambios en los últimos cuarenta años en múltiples ámbitos (la demografía, la tecnología, la economía, etc.), haciendo que el poder se vuelva más difícil de adquirir y, a su vez, de defender. Naím agrupa dichos cambios en tres categorías de transformaciones revolucionarias que, según él, definen nuestro tiempo: "la revolución del más, que se caracteriza por el aumento, la abundancia de todo (el número de países, la población, el nivel de vida, las tasas de alfabetización, el incremento de la salud y la cantidad de productos, partidos políticos y religiones); la revolución de la movilidad, que capta el hecho de que no solo hay más de todo sino que ese más (gente, productos, tecnología, dinero) se mueve más que nunca y a menor coste, y llega a todas partes, incluso a lugares que hasta hace poco eran inaccesibles, y la revolución de la mentalidad, que refleja los grandes cambios de modos de pensar, expectativas y aspiraciones que han acompañado a estas transformaciones" (p. 32).

El libro no trata una simple transferencia de poder de un protagonista a otro, el debate que realmente abre es, que está cambiando la naturaleza misma del poder. Ahora, no se trata tampoco de negar que el presidente de los Estados Unidos tiene poder, o que el Papa tiene poder, o que Google o los presidentes de los Bancos tienen mucho poder; se trata de que a pesar de tenerlo, son más vulnerables, más débiles, que quienes ocuparon esos mismos cargos años atrás. El poder se está degradando. Esto no es nuevo, a menudo se habla de ello y se tiende a atribuir todos estos cambios a la aparición del internet -a las nuevas tecnologías de la información-; sin embargo, esta explicación, en la opinión de Naím, es demasiado simplista y se queda corta.

"En concentro, este libro cuestiona
dos de los temas más habituales en las
conversaciones sobre el poder en estos
tiempos. Uno de ellos es la obsesión por
internet como explicación de los cambios
en el poder, sobre todo en la política y la
economía. El otro es la obsesión por el
cambio de guardia en la geopolítica, que 
afirma que el declive de algunas naciones (en especial Estados Unidos) y el ascenso de otras (sobre todo China) son la tendencia que más está transformando el mundo actual" (Naím, 2013, p. 35)

Entonces, ¿quién o quiénes están impidiendo que los viejos y grandes actores tengan más limitaciones que nunca para ejercer el poder que sin duda tienen? "Son los micropoderes: actores pequeños, desconocidos o antes insignificantes, que han encontrado formas de socavar, acorralar o desmontar las megapotencias, estas grandes organizaciones burocráticas que antes dominaban sus ámbitos de actuación" (Naím, 2013, p. 86). Las tres revoluciones (más, movilidad, mentalidad) han cambiado la manera de pensar de las personas sobre la vida, “(...) Cuando una persona está mejor alimentada y es más sana, más educada, está mejor informada y más relacionada con otros, muchos de los factores que mantenían el poder en su sitio dejan de ser eficaces" (p. 95). Las personas ahora son más difíciles de regular, dominar y controlar.

El fin del Poder es un libro completo, en el sentido de que no solo se limita a describir unos planteamientos -que ya resumí-: no solo expone qué, cómo y por qué ha pasado lo que ha pasado respecto al poder y sus cambios; de igual forma, y muy importante a mi parecer, dedica sus dos últimos capítulos (capítulo 10 y capítulo 11) a explicar las implicaciones de su tesis, y la importancia de tomar acciones frente a dichos cambios. El capítulo 10, titulado La degradación del poder: ¿el vaso está medio lleno o medio vacío? Expone las implicaciones tanto positivas como negativas de la degradación del poder: "La degradación del poder tiene consecuencias indudablemente positivas: sociedades más libres, más oportunidades de elección para los votantes, nuevas plataformas para organizar comunidades, más ideas y posibilidades, más inversión y comercio, más competencia entre empresas y, por lo tanto, más opciones para los consumidores" (p. 320), lo anterior hablando en términos generales, por supuesto que se pueden encontrar excepciones desalentadoras; ahora, también tiene implicaciones negativas: “(...) fomenta también la aparición de infinidad de grupos criminales, terroristas, y otros que atentan contra la seguridad ciudadana y en algunos casos hasta erosionan la estabilidad internacional" (p. 323). El capítulo $11-\mathrm{y}$ último- del libro, El poder se degrada. ¿Y eso qué importa? ¿Qué podemos 
hacer?, el escritor venezolano expone sus conclusiones y sugerencias respecto a qué rumbo debe tomar el mundo para que el impacto de dichos cambios, sea positivo. La conclusión "quizá (...) más importante, es la urgente necesidad de cambiar nuestra forma de pensar acerca del poder" (p. 340).

Dijo Bill Clinton "El Fin del Poder cambiará tu manera de leer las noticias, tu manera de pensar en política y tu manera de mirar al mundo", creo que de una u otra manera, tiene razón, este libro, por lo menos nos hará poder contrastar con otro punto de vista los cambios que ocurren y ocurrirán en el ámbito de la política internacional. 